\title{
Isoquinoline alkaloids from Zanthoxylum simulans and their biological evaluation
}

\author{
Sheng-Hui Yang ${ }^{1,4}$, Yan-Qun Liu ${ }^{1,4}$, Jun-Feng Wang 2 , Yue-Hu Wang ${ }^{3}$, Wei-Wei Pan ${ }^{1}$, Wen-Bing Sheng ${ }^{1}$, \\ Rui Cai ${ }^{1}$ and Xiao-Jiang Zhou ${ }^{1}$
}

The Journal of Antibiotics (2015) 68, 289-292; doi:10.1038/ja.2014.139; published online 1 October 2014

Rheumatoid arthritis (RA) is a chronic inflammatory autoimmune disease characterized by synovial inflammation, destruction of joint cartilage and bone erosion, it affected 0.5 to $1 \%$ of the population. ${ }^{1-4}$ At the present, the treatment of RA often involves the extensive use of disease-modifying anti-rheumatic drugs and anti-rheumatic biological drugs, such as methotrexate, salazosulfapyridine, iguratimod, tofacitinib and so on..$^{5-7}$ However, more attention has been focused on traditional Chinese medicine by their efficacy against RA and safety, for example, sinomenine that is extracted from Sinomenium acutum has shown therapeutic efficacy and few side effects in patients with RA in China since the 1990ss. ${ }^{8,9}$ Natural products have provided unlimited opportunities for new drug discoveries because of their inherent chemical diversity, and have prompted a continuous research for plant sources with medicinal value. Zanthoxylum simulans belongs to the genus Zanthoxylum of Rutaceae family. The barks are commonly used for the treatment of RA and swelling with unknown reasons in traditional Chinese medicine. ${ }^{10}$ Previous chemical investigations on this genus have led to the identification of a series of alkaloids, coumarins, amides, lignans and flavonoids. ${ }^{11-15}$ However, the specific components responsible for the therapeutic effects of this traditional Chinese medicine are still not well clarified. In our ongoing study to seek bioactive constituents from this traditional Chinese medicine against RA, we isolated a series of isoquinoline alkaloids, including three new alkaloids, zanthoxylumines A-C (1-3), together with six known compounds (Figure 1), 6-acetonyl- $N$-methyldihydrodecarine (4), ${ }^{16}$ 8-hydroxy-7-methoxy-5-methyl-2,3-meth-ylenedioxybenzo $[c]$ phenanthridin-6(5H)-one (5), ${ }^{17}$ decarine $(6),{ }^{18}$ norchelerythrine (7), ${ }^{18}$ liriodenine $(\mathbf{8})^{19}$ and lysicamine (9). ${ }^{19}$ Their structures were elucidated using extensive spectroscopic techniques. The isolated compounds were evaluated for their inhibitory activities against rat joint synovial cell proliferation, splenocyte proliferation and antimicrobial activities. We present herein the extraction, isolation, structure elucidation and biological activities of compounds 1-9.

Compound 1 was obtained as white solid, and had a molecular formula $\mathrm{C}_{19} \mathrm{H}_{15} \mathrm{NO}_{4}$ from the high resolution electron ionization mass spectra (HREIMS) $\left(\mathrm{m} / \mathrm{z} 321.0992[\mathrm{M}]^{+}\right.$, calcd 321.1001). The ${ }^{1} \mathrm{H}$ and ${ }^{13} \mathrm{C}$ NMR data (Table 1) showed the characteristic pattern of a benzophenanthridine alkaloid. ${ }^{16-18}$ The ${ }^{1} \mathrm{H}$ NMR spectrum exhibited signals at $\delta_{\mathrm{H}} 7.56(\mathrm{~d}, J=8.9 \mathrm{~Hz}), 8.40(\mathrm{~d}, J=8.9 \mathrm{~Hz}), 8.41(\mathrm{~d}$, $J=8.9 \mathrm{~Hz}), 7.84(\mathrm{~d}, J=8.9 \mathrm{~Hz}), 7.31(\mathrm{~s}), 8.62(\mathrm{~s})$ and $9.58(\mathrm{~s})$, indicating the presence of four aromatic hydrogens in ortho position and three isolated hydrogens, and it can be confirmed by the crosspeaks between $\mathrm{H}-9\left(\delta_{\mathrm{H}} 7.56\right)$ and $\mathrm{H}-10\left(\delta_{\mathrm{H}} 8.40\right), \mathrm{H}-11\left(\delta_{\mathrm{H}} 8.41\right)$ and $\mathrm{H}-12\left(\delta_{\mathrm{H}} 7.84\right)$ in the $1 \mathrm{H}-1 \mathrm{H}$ COSY spectrum. Detailed analysis of the one-dimensional and two-dimensional NMR spectra data revealed that the NMR data of $\mathbf{1}$ were very similar to those of decarine (6), ${ }^{18}$ except for the signals for the methylenedioxide group in decarine (6) were replaced by those for one methoxy group and one hydroxyl group in compound 1 . The methoxy group was assigned by the correlation from $3-\mathrm{OCH}_{3}$ to $\mathrm{C}-3$ in the $\mathrm{HMBC}$ spectrum (Figure 2). The ROESY spectrum showed the correlations between protons $\mathrm{H}-12$ and $\mathrm{H}-1 / \mathrm{H}-11, \mathrm{H}-9$ and $\mathrm{H}-10$ (Figure 2). Therefore, compound 1 was elucidated as 2,8-dihydroxy-3,7-dimethoxybenzo[c]phenanthridine and named zanthoxylumine A.

Compound 2 was isolated as white solid. Its molecular formula was determined as $\mathrm{C}_{20} \mathrm{H}_{17} \mathrm{NO}_{4}$ on the basis of the HREIMS ( $\mathrm{m} / z 335.1155$ $[\mathrm{M}]^{+}$, calcd 335.1158). The ${ }^{1} \mathrm{H}$ and ${ }^{13} \mathrm{C}$ NMR data (Table 1) indicated that the structure of $\mathbf{2}$ was closely similar to that of $\mathbf{1}$, differing in one more $O$-methyl in the structure of 2 , which was also supported by the correlation from $2-\mathrm{OCH}_{3}$ to $\mathrm{C}-2$ in the $\mathrm{HMBC}$ spectrum (Figure 2). The ROESY spectrum showed the correlations between protons $\mathrm{H}-12$ and $\mathrm{H}-1 / \mathrm{H}-11, \mathrm{H}-9$ and $\mathrm{H}-10$ (Figure 2). Thus, compound 2 was

${ }^{1}$ College of Pharmacy, Hunan University of Chinese Medicine, Changsha, China; ${ }^{2}$ CAS Key Laboratory of Tropical Marine Bio-resources and Ecology/Guangdong Key Laboratory of Marine Materia Medica/RNAM Center for Marine Microbiology, South China Sea Institute of Oceanology, Chinese Academy of Sciences, Guangzhou, China and ${ }^{3}$ State Key Laboratory of Phytochemistry and Plant Resources in West China, Kunming Institute of Botany, Chinese Academy of Sciences, Kunming, China

${ }^{4}$ These authors contributed equally to this work.

Correspondence: Dr J-F Wang, CAS Key Laboratory of Tropical Marine Bio-resources and Ecology/Guangdong Key Laboratory of Marine Materia Medica/RNAM Center for Marine Microbiology, South China Sea Institute of Oceanology, Chinese Academy of Sciences, Guangzhou 510301, China.

E-mail: wangjunfeng@scsio.ac.cn

or Professor X-J Zhou, College of Pharmacy, Hunan University of Chinese Medicine, Changsha 410208, China.

E-mail: gale9888@163.com

Received 30 June 2014; revised 29 August 2014; accepted 3 September 2014; published online 1 October 2014 
<smiles>[R]Oc1cc2ccc3c4ccc(O)c(OC)c4ncc3c2cc1OC</smiles><smiles>COc1c(O)ccc2c1[C@@H](C(C)(C)O)N(C)c1c-2ccc2cc3c(cc12)OCO3</smiles><smiles>COc1c(O)ccc2c1[C@@H](CC(C)=O)N(C)c1c-2ccc2cc3c(cc12)OCO3</smiles><smiles>COc1c(O)ccc2c1c(=O)n(C)c1c3cc4c(cc3ccc21)OCO4</smiles><smiles>[R]Oc1ccc2c(cnc3c4cc5c(cc4ccc23)OCO5)c1OC</smiles><smiles>[R]Oc1cc2ccnc3c2c(c1O[R20])-c1ccccc1C3=O</smiles>

Figure 1 Chemical structures of compounds 1-9.

Table $1{ }^{1} \mathrm{H}$ and ${ }^{13} \mathrm{C}$ NMR Data of compounds $1-3$ (600 and $150 \mathrm{MHz}$, respectively, $\delta$ in p.p.m.)

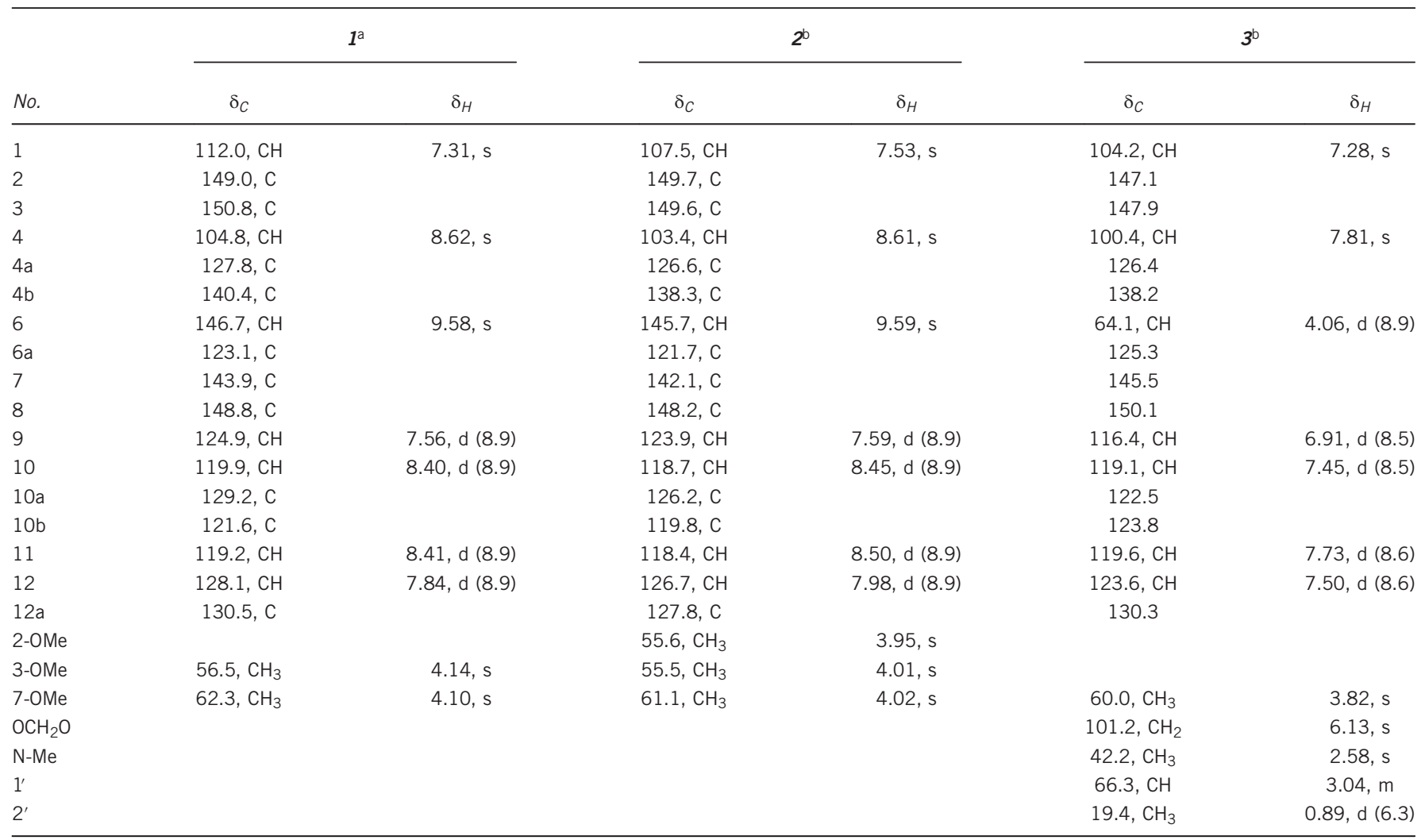

${ }^{\text {a }}$ Measured in $\mathrm{CD}_{3} \mathrm{OD}$.

${ }^{b}$ Measured in dimethyl sulfoxide- $\mathrm{d}_{6}$.

elucidated as 8-hydroxy-2,3,7-trimethoxybenzo[c]phenanthridine and named zanthoxylumine B.

Compound 3 was obtained as white solid, gave an HREIMS peak at $\mathrm{m} / z 379.1423[\mathrm{M}]^{+}$, corresponding to the molecular formula $\mathrm{C}_{22} \mathrm{H}_{21} \mathrm{NO}_{5}$. The ${ }^{1} \mathrm{H}$ and ${ }^{13} \mathrm{C}$ NMR data (Table 1) also implied the characteristic pattern of a benzophenanthridine alkaloid as compounds 1 and 2. Comparison of all NMR data with those of 6-acetonyl- $N$-methyldihydrodecarine (4) whic h was recently isolated from $Z$. riedelianum, ${ }^{16}$ revealed a high degree of similarity. However, the only difference between them was the presence of 1-hydroxyethyl moiety instead of one acetonyl group. The 1-hydroxyethyl was located at C-6 by the cross-peaks between $\mathrm{H}-1^{\prime}\left(\delta_{\mathrm{H}} 3.04\right)$ and $\mathrm{H}-6\left(\delta_{\mathrm{H}} 4.06\right) /$ $\mathrm{H}_{3}-2^{\prime}\left(\delta_{\mathrm{H}} 0.89\right)$ in the $1 \mathrm{H}-1 \mathrm{H}$ COSY spectrum and the correlation of $\delta_{\mathrm{H}} 0.89\left(\mathrm{H}_{3}-2^{\prime}\right) / \mathrm{C}-6$ in the HMBC spectrum (Figure 2). The ROESY spectrum showed the key correlations of $\mathrm{H}-6$ with $\mathrm{H}-1^{\prime}$, $\mathrm{H}_{3}-2^{\prime}$ and $5-\mathrm{NCH}_{3}$ (Figure 2), consistent with 6-acetonyl$\mathrm{N}$-methyldihydrodecarine (4). ${ }^{16}$ Consequently, compound 3 was determined as 6-(1-hydroxyethyl)- $N$-methyldihydrodecarine and named zanthoxylumine $\mathrm{C}$.

All the isolated compounds were evaluated for their inhibitory activities against rat joint synovial cells proliferation, splenocytes proliferation and antimicrobial activities, respectively. Among them, 

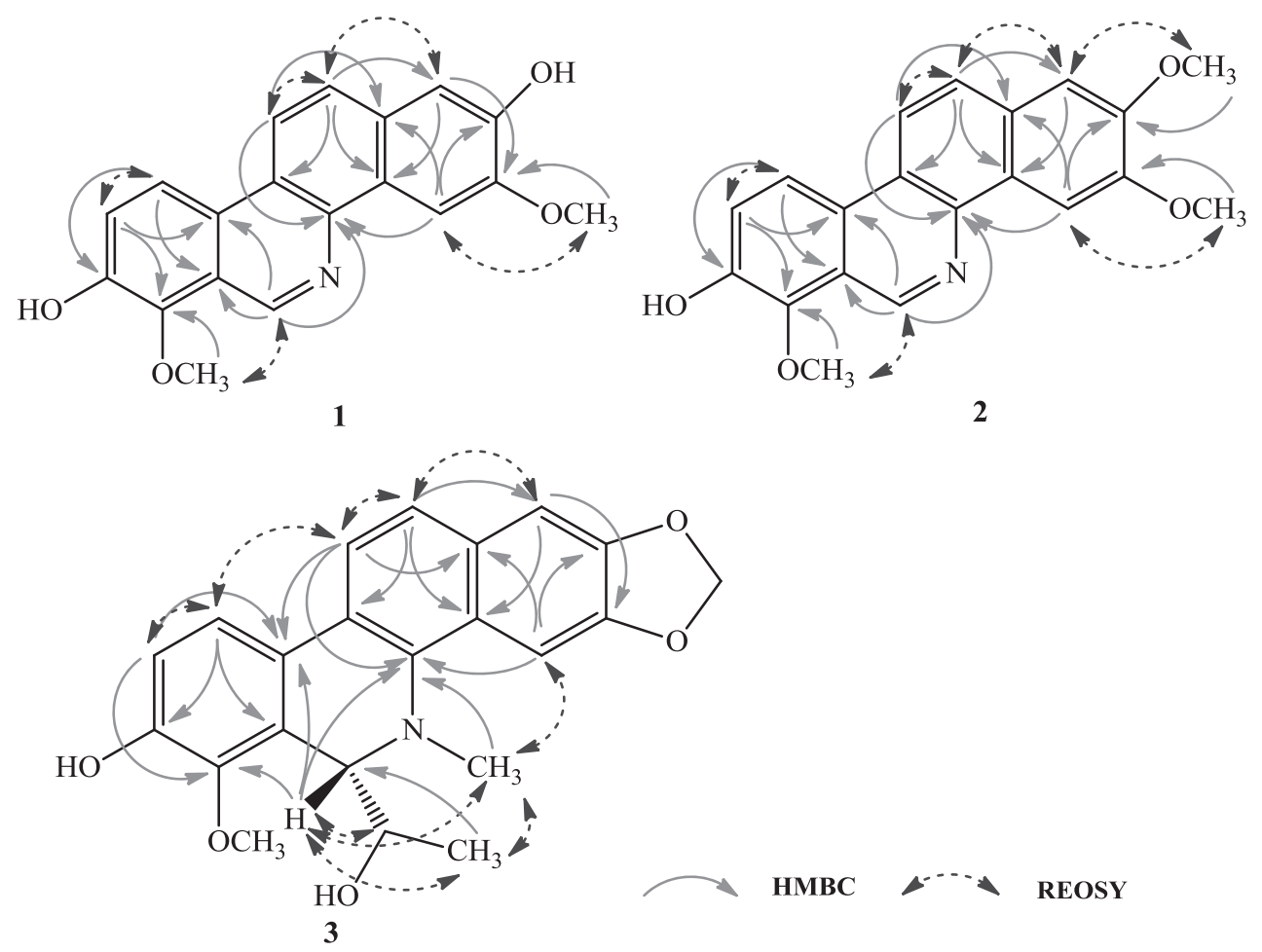

Figure 2 The key HMBC and ROESY correlations of 1-3. A full color version of this figure is available at The Journal of Antibiotics journal online.

Table 2 Inhibitory activities of compounds $1-9\left(\mathrm{IC}_{50}, \mu \mathrm{M}\right)$

\begin{tabular}{lcc}
\hline Compound & Rat joint synovial cells & Splenocytes \\
\hline $\mathbf{1}$ & 25.0 & 57.7 \\
$\mathbf{2}$ & 32.2 & 49.7 \\
$\mathbf{3}$ & $>50$ & 39.1 \\
$\mathbf{4}$ & 38.1 & $>60$ \\
$\mathbf{5}$ & $>50$ & $>60$ \\
$\mathbf{6}$ & 24.2 & $>60$ \\
$\mathbf{7}$ & 35.3 & $>60$ \\
$\mathbf{8}$ & 35.6 & 22.2 \\
$\mathbf{9}$ & 25.3 & $>60$ \\
Sinomenine & 16.9 & 22.6 \\
\hline
\end{tabular}

compounds 1, 2, 4 and 6-9 exhibited inhibitory activities against rat joint synovial cells proliferation with $\mathrm{IC}_{50}$ values ranging from 24.2 to $38.1 \mu \mathrm{M}$, and compounds $\mathbf{1}-\mathbf{3}$ and $\mathbf{8}$ exhibited inhibitory activities against splenocytes proliferation with $\mathrm{IC}_{50}$ values ranging from 22.2 to $57.7 \mu \mathrm{M}$, respectively (Table 2). In addition, compounds 1 and 4 showed modest antimicrobial activities against Enterococcus faecalis with MIC values of 23.4 and $12.8 \mu \mathrm{M}$, respectively. This study not only provides a scientific rationale between the biological activity and the herbal remedies of this plant but also discloses compounds 1-4 and 6-9, which may serve as potential drugs against RA for future clinical treatment.

\section{MATERIALS AND METHODS}

\section{General experimental procedures}

Optical rotations were recorded on a Horiba SEPA-300 polarimeter. UV spectra were measured on a Shimadzu UV-2401PC spectrophotometer (Shimadzu Corporation, Kyoto, Japan). IR spectra were obtained on a Tensor 27 (Bruker
Optics Gmbh, Ettlingen, Germany) with $\mathrm{KBr}$ pellets. NMR spectra were recorded on the Bruker AV-400, DRX 500 and Bruker Avance III- $600 \mathrm{MHz}$ spectrometer (Bruker BioSpin GmbH, Rheinstetten, Germany). EI-MS was obtained on a Finnigan-4510 spectrometer. ESI-MS and HREIMS were determined with an API QSTAR Pulsar 1 spectrometer (MDS Sciex, Concord, ON, Canada). Silica gel (200-300 mesh, Qingdao Marine Chemical Qingdao, China), RP-18 gel (40-63 $\mu$ m, Daiso, Osaka, Japan), and Sephadex LH-20 (Amersham Biosciences, Uppsala, Sweden) were used for column chromatography. Semi-preparative HPLC (SHIMADZU LC-10A HPLC system (Shimadzu Corporation), Ultimate XB-C-18, $5 \mu \mathrm{m}, 10 \times 250 \mathrm{~mm}$ ).

\section{Plant materials}

The barks of $Z$. simulans $(30 \mathrm{~kg})$ were purchased from Hunan Corporation of Materia Medica, Hunan Province, China, in February 2011, and authenticated by corresponding author (XJZ). A voucher specimen (ZHXJ-0012) was deposited at our laboratory in Hunan University of Chinese Medicine.

\section{Extraction and isolation}

The dried powdered bark of $Z$. simulans $(30 \mathrm{~kg}$ ) was extracted with ethanol $(2 \times 180 \mathrm{l})$ to yield an extract $(3370 \mathrm{~g})$, which was suspended in water and partitioned by petroleum ether and EtOAc (each $4 \times 81$ ). The EtOAc extract ( $470 \mathrm{~g}$ ) was fractionated by a silica gel column eluted with $\mathrm{CHCl}_{3}$ with increasing amounts of methanol to yield seven fractions (Frs 1-7). Fr 2 (89 g) was divided into five parts (Frs 2-1-2-5) by an MCI gel CHP $20 \mathrm{P}$ column eluting with gradient aqueous $\mathrm{MeOH}$. Fr 2-3 (9.5 g) chromatographed by silica gel column (petroleum ether/EtOAc, 20:1, 15:1, 10:1, 5:1, 2:1, 1:1) to separate three parts (Frs 2-3-1-2-3-3), compound 1 (9.3 mg) was purified by RP-18 gel column $\left(\mathrm{MeOH}-\mathrm{H}_{2} \mathrm{O}\right.$ 1:1-1:0), silica gel column (petroleum ether/EtOAc, 4:1) and Sephadex LH-20 (MeOH) from Fr 2-3-3 (1.8 g). Fr 2-3-1 (1.4 g) first submitted by RP-18 gel column (MeOH- $\mathrm{H}_{2} \mathrm{O}$ 1:1-1:0), followed by Sephadex LH-20 (MeOH) and further purified by semi-preparative HPLC (SHIMADZU LC-10A HPLC system, Ultimate XB-C-18, $5 \mu \mathrm{m}, 10 \times 250 \mathrm{~mm}$ ) eluting with $75 \%$ aqueous $\mathrm{MeOH}$ to yield compound $6(10.5 \mathrm{mg})$ and compound 7 
(12.8 mg). Fr 2-4 (11.1 g) was chromatographed by vaccum liquid chromatography on a silica gel column eluted with petroleum ether/EtOAc (10:1, 5:1, 10:1, 4:1, 3:1, 2:1, 1:1) to divide into four parts (Frs 2-4-1-2-4-4). Frs 2-4-1 $(2.9 \mathrm{~g})$ was first chromatographed by RP-18 gel column ( $\mathrm{MeOH}-\mathrm{H}_{2} \mathrm{O}$ 1:1-1:0), followed by Sephadex $\mathrm{LH}-20(\mathrm{MeOH})$, and finally purified by semi-preparative HPLC (64\% aqueous $\mathrm{MeOH})$ to yield compound $2(8.1 \mathrm{mg})$ and compound 3 $(14.0 \mathrm{mg})$. Fr 2-4-2 $(1.3 \mathrm{~g})$ was separated by RP-18 gel column $\left(\mathrm{MeOH}-\mathrm{H}_{2} \mathrm{O}\right.$ 1:1-1:0) and followed by semi-preparative HPLC (70\% aqueous $\mathrm{MeOH})$ to yield compound $4(17.5 \mathrm{mg})$ and compound $5(7.2 \mathrm{mg})$. Fr 2-2 (7.2 g) was first submitted to silica gel column (petroleum ether/EtOAc, 30:1, 25:1, 20:1, 15:1, 10:1, 5:1, 1:1), followed by Sephadex LH-20 (MeOH) and RP-18 gel column $\left(\mathrm{MeOH}-\mathrm{H}_{2} \mathrm{O} 4: 6-1: 0\right)$ to produce compound $8(6.3 \mathrm{mg})$ and compound 9 (45.1 mg).

Zanthoxylumine A (1). White solid; UV (MeOH) $\lambda_{\max }(\log \varepsilon) 274.5$ (2.85), $252.0(2.83)$ and $202.0(2.78) \mathrm{nm}$; IR (KBr) $\nu_{\max } 3441,1630,1464,1456$ and $1384 \mathrm{~cm}^{-1}$; ${ }^{1} \mathrm{H}$ and ${ }^{13} \mathrm{C}$ NMR data, see Table 1; EIMS $\mathrm{m} / z 321[\mathrm{M}]^{+}$; HREIMS $321.0992[\mathrm{M}]^{+}$(calcd for $\mathrm{C}_{19} \mathrm{H}_{15} \mathrm{NO}_{4}, 321.1001$ ).

Zanthoxylumine B (2). White solid; UV (MeOH) $\lambda_{\max }(\log \varepsilon) 274.0$ (3.95) and $206.5(3.84) \mathrm{nm}$; IR (KBr) $\nu_{\max } 3441,1626,1462,1438$ and $1384 \mathrm{~cm}^{-1} ;{ }^{1} \mathrm{H}$ and ${ }^{13} \mathrm{C}$ NMR data, see Table 1; EIMS $m / z 335$ [M] ${ }^{+}$; HREIMS $335.1155[\mathrm{M}]^{+}$ (calcd for $\mathrm{C}_{20} \mathrm{H}_{17} \mathrm{NO}_{4}, 335.1158$ ).

Zanthoxylumine C (3). White solid; $[\alpha]^{15.4}{ }_{\mathrm{D}}-7.2(c$ 0.10, MeOH); UV $(\mathrm{MeOH}) \lambda_{\max }(\log \varepsilon)=282.4(4.08)$ and $227.2(4.01) \mathrm{nm}$; IR $(\mathrm{KBr}) \nu_{\max } 3448$, 1635, 1486, 1423 and $1384 \mathrm{~cm}^{-1} ;{ }^{1} \mathrm{H}$ and ${ }^{13} \mathrm{C}$ NMR data, see Table 1 ; ESIMS $m / z=380[\mathrm{M}+\mathrm{H}]^{+}$; HREIMS $379.1423[\mathrm{M}]^{+}$(calcd. for $\mathrm{C}_{22} \mathrm{H}_{21} \mathrm{NO}_{5}$, 379.1420).

One-dimensional and Two-dimensional NMR and HREIMS spectra of compounds 1-3 and bioassay protocols are available in Supplementary Information.

\section{ACKNOWLEDGEMENTS}

This work was supported by the National Natural Science Foundation of China (No. 31170336), Hunan Province University Innovation Platform Open Foundation, China (No. 12K085) and Science Projects Foundation of Changsha Municipal Science and Technology Bureau, China (No. K1308013-31).
1 Feldmann, M., Brennan, F. M, Maini, R. N. Rheumatoid arthritis. Cell 85, 307-310 (1996)

2 Kang, K. Y., Woo, J., Park, S. S100A8/A9 as a biomarker for synovial inflammation and joint damage in patients with rheumatoid arthritis. Korean J. Intern. Med. 29, 12-19 (2014).

3 Too, C. L. et al. Increased igG rheumatoid factor-positivity in the Asian rheumatoid arthritis patients irrespective of ethnicity. Open J. Rheumatol. Auto. Dis. 4, 43-51 (2014).

4 Kumagai, H., Masuda, T., Ohba, S., Ikeda, D. Suppression of type Ilcollagen-induced arthritis by ICM0301B, a new angiogenesis inhibitor. J. Antibiot. 66, 243-246 (2013).

5 Malemud, J. C. Intracellular signaling pathways in rheumatoid arthritis. J. Clin. Cell Immunol. 4, 160-167 (2013).

6 Suematsu, A. et al. Scientific basis for the efficacy of combined use of antirheumatic drugs against bone destruction in rheumatoid arthritis. Mod. Rheumatol. 17, 17-23 (2007).

7 Kohno, M. et al. Inhibitory effect of T-614 on tumor necrosis factor-alpha induced cytokine production and nuclear factor-kappaB activation in cultured human synovial cells. J. Rheumatol. 28: 2591-2596 (2001).

8 Moudgil, K. D., Berman, B. M. Traditional Chinese medicine: potential for clinica treatment of rheumatoid arthritis. Expert Rev. Clin. Immunol. 10, 819-822 (2014).

9 Zhao, X. X., Peng, C., Zhang, H., Qin, L. P. Sinomenium acutum: a review of chemistry, pharmacology, pharmacokinetics, and clinical use. Pharm. Biol. 50, 1053-1061 (2012).

10 Zhonghua Bencao Editorial Committee Zhonghua Bencao Shanghai Scientific and Technological: Shanghai, Vol. 12, 994 (1999).

11 Munoz, M. A., Torres, R., Cassels, B. K. Aurapten and flindersine from Zanthoxylum coco. J. Nat. Prod. 45, 367-369 (1982).

12 Kato, A., Moriyasu, M., Ichimaru, M., Nishiyama, Y. Isolation of alkaloidal constituents of Zanthoxylum usambarense and Zanthoxylum chalybeum using ion-pair HPLC. J. Nat. Prod. 59, 316-318 (1996).

13 Kalia, N. K., Singh, B., Sood, R. P. A new amide from Zanthoxylum armatum. J. Nat. Prod. 62, 311-312 (1999).

$14 \mathrm{Li}, \mathrm{W}$. et al. Coumarins and lignans from Zanthoxylum schinifolium and their anticancer activities. J. Agric. Food Chem. 61: 10730-10740 (2013).

$15 \mathrm{Zhou}, \mathrm{X}$. J. et al. Two dimeric lignans with an unusual $\alpha, \beta$-unsaturated ketone motif from Zanthoxylum podocarpum and their inhibitory effects on nitric oxide production. Bioorg. Med. Chem. Lett. 21: 373-376 (2011).

16 Fernandes, C. C. et al. 6-acetonyl- $N$-methyl-dihydrodecarine, a new alkaloid from Zanthoxylum riedelianum. J. Braz. Chem. Soc 20: 379-382 (2009).

17 Ishikawa, T. et al. Concise syntheses of the oxo derivatives of benzo[c]phenanthridine bases by $\mathrm{N}$-deformylated cyclization based on Vilsmeier-Haack reaction. Chem. Pharm. Bull. 43: 766-770 (1995).

18 Martin, M. T., Rasoanaivo, L. H., Raharisololalao, A. Phenanthridine alkaloids from Zanthoxylum madagascariense. Fitoterapia 76, 590-593 (2005).

19 Zhang, Z. Z. et al. New sesquiterpenoids from the root of Guatteria multivenia. J. Nat Prod. 65: 856-859 (2002).

Supplementary Information accompanies the paper on The Journal of Antibiotics website (http://www.nature.com/ja) 